University of Texas at El Paso

ScholarWorks@UTEP

$9-2013$

\title{
Perception of Elite and Universal Systems of Higher Education: An Explanation of the Empirical Thresholds
}

Olga Kosheleva

The University of Texas at El Paso, olgak@utep.edu

Vladik Kreinovich

The University of Texas at El Paso, vladik@utep.edu

Follow this and additional works at: https://scholarworks.utep.edu/cs_techrep

Part of the Educational Assessment, Evaluation, and Research Commons, and the Higher Education Commons

Comments:

Technical Report: UTEP-CS-13-61

\section{Recommended Citation}

Kosheleva, Olga and Kreinovich, Vladik, "Perception of Elite and Universal Systems of Higher Education: An Explanation of the Empirical Thresholds" (2013). Departmental Technical Reports (CS). 773.

https://scholarworks.utep.edu/cs_techrep/773

This Article is brought to you for free and open access by the Computer Science at ScholarWorks@UTEP. It has been accepted for inclusion in Departmental Technical Reports (CS) by an authorized administrator of ScholarWorks@UTEP.For more information, please contact Iweber@utep.edu. 


\title{
PERCEPTION OF ELITE
}

\section{AND UNIVERSAL SYSTEMS \\ OF HIGHER EDUCATION: \\ AN EXPLANATION OF THE \\ EMPIRICAL THRESHOLDS}

\author{
Olga Kosheleva ${ }^{1}$ and Vladik Kreinovich ${ }^{2}$ \\ ${ }^{1}$ Department of Teacher Education \\ ${ }^{2}$ Department of Computer Science \\ University of Texas at El Paso \\ $500 \mathrm{~W}$. University \\ El Paso, TX 79968, USA \\ olgak@utep.edu,vladik@utep.edu
}

\begin{abstract}
Systems of higher education are usually divided into elite, mass, and universal, depending on the proportion of young people who attend college. Human experts perceive a system as elite is less than $15 \%$ of young people of the 18-21 age group attend college, and as universal if more than $40 \%$ of young people of this age group attend college. The corresponding $15 \%$ and $40 \%$ thresholds are, however, purely empirical. In this paper, we provide an explanation for these empirical thresholds - an explanation based on the known psychological $7 \pm 2$ law.
\end{abstract}

Mathematics Subject Classification: 91E45, 97B40

Keywords: higher education, elite, universal, perception, 7 plus minus 2

\section{Perception of Elite and Universal Systems of Higher Education: Empirical Thresholds}

Types of higher education systems. Different countries' systems of higher education are commonly divided into three categories, depending on the proportion of young people between 18 and 21 years of age who attend college: 
- When very few young people of this age group attend college, the system is perceived as elite.

- When close to a half (or more) young people of this age group attend college, the system is perceived as universal.

- In intermediate cases, the system is perceived as mass.

Perception of elite and universal systems: empirical thresholds. After analyzing human perceptions of what constitutes an elite system and what constitutes a universal system, researches came up with the following empirical thresholds (see, e.g., $[1,3]$ ):

- countries with fewer than $15 \%$ of young people of the 18-21 age group attending college are perceived to have an elite system;

- countries with $15 \%$ to $40 \%$ of young people of the 18-21 age group attending college are perceived to have a mass system; and

- countries with more than $40 \%$ of young people of the 18-21 age group attending college are perceived to have a universal system.

Problem: how to explain these empirical thresholds? How can we explain these empirical thresholds? Why do these specific thresholds - of approximately $15 \%$ and of approximately $40 \%$ - reflect the human perception of elite and universal systems?

What we do in this paper. In this paper, we present a possible explanation for the empirically observed thresholds.

\section{Explanation of the Empirical Thresholds}

What is elite: analysis of the problem. Intuitively, an elite is something which is not reflected in the usual classification of population into groups.

For example, in the city of Houston, approximately half of the population is white, approximately a third is Hispanic, and approximately a quarter is African-American. From this demographic viewpoint, it is reasonable to classify people from Houston into these three categories. In Houston, there are also cultural elites, political elites, etc.; these elites are important, but they do not immediately come to mind in a natural classification of the city's population. 
From an idea to a numerical estimate. How can we transform the above idea into a numerical estimate? It is known that, in general, when asked to classify, people divide objects into $7 \pm 2$ categories; see, e.g., [5, 6] (see also $[2,4]$; a possible explanation is given in [7]). This means that on average, people divide objects into 7 categories.

These categories are usually of the same size. Thus, when we divide people into categories, each category comprises approximately $1 / 7 \approx 14 \%$ of the population group. This leads us to the following conclusion:

- When a group of people constitutes $14 \%$ of more of a population, it is perceived as one of the normal groups - and thus, not as a small elite.

- On the other hand, when a group of people constitutes less than $14 \%$ of the population, it is highly probable that this group will not appear in a natural classification - and thus, members of this groups are perceived as an elite.

Discussion. The above explanation comes up with a $14 \%$ threshold instead of the desired 15\%. At first glance, it may seem like a discrepancy; however, in reality:

- first, the empirical values $15 \%$ and $40 \%$ are approximate;

- second, 7 is also an approximate number.

The prevalence of 7 means that the actual portion is closer to $1 / 7 \approx 14 \%$ than to $1 / 6 \approx 17 \%$ or to $1 / 8 \approx 13 \%$. From this viewpoint, the empirical $15 \%$ value is definitely closer to $14 \%$ than to $17 \%$ or to $13 \%$, so $14 \%$ is a good fit for $15 \%$.

Conclusion: we have explained the elite threshold. The above idea explains why $\approx 15 \%$ is an empirically observed threshold for elite systems of higher education.

What is universal: analysis of the problem. Intuitively, as we have mentioned, universal means close to $1 / 2$ or larger. By definition, a non-elite group comprises one or more categories in a natural classification.

As we have mentioned, a natural classification consists, on average, of seven categories of approximately equal size. An exact half of the population means that the group comprises three to four categories. So, almost half or more means three of more categories. A group that comprises three or more categories - out of seven approximately equal groups - contains at least $3 / 7 \approx 43 \%$ of the population. Thus, intuitively:

- When a group of people constitutes $43 \%$ of more of a population, it is perceived as universal. 
- On the other hand, when a group of people constitutes less than $43 \%$ of the population, it is not perceived as universal.

Discussion. The above explanation come up with a $43 \%$ threshold instead of the desired $40 \%$. Just like in the elite case, this is reasonable:

- the empirical values $15 \%$ and $40 \%$ are approximate, and

- 7 is an approximate number.

The prevalence of 7 means that the actual portion is closer to $3 / 7 \approx 43 \%$ than to $3 / 6 \approx 50 \%$ or ro $2 / 6 \approx 33 \%$ (or to $4 / 8 \approx 50 \%$ ). From this viewpoint, the empirical $40 \%$ value is definitely closer to $43 \%$ than to $50 \%$ or to $33 \%$, so $43 \%$ is a good fir for $40 \%$.

Conclusion: we have explained the universality threshold. The above idea explains why $\approx 40 \%$ is an empirically observed threshold for universal systems of higher education.

Acknowledgments. This work was supported in part by the National Science Foundation grants HRD-0734825 and HRD-1242122 (Cyber-ShARE Center of Excellence) and DUE-0926721, by Grants 1 T36 GM078000-01 and 1R43TR000173-01 from the National Institutes of Health, and by a grant N62909-12-1-7039 from the Office of Naval Research.

\section{References}

[1] D. Bok, Higher Education in America, Princeton University Press, Princeton, New Jersey, 2013.

[2] P. Bonissone and K. Decker, "Selecting Uncertainty Calculi and Granularity: An Experiment in Trading-off Precision and Complexity", In: L. N. Kanal and J. F. Lemmer (eds.), Uncertainty in Artificial Intelligence, North Holland, Amsterdam, 1986, pp. 217 - 247.

[3] J. A. Douglass, J. King, and I. Feller (eds.), Globalization's Muse: Universities and Higher Education Systems in a Changing World, Berkeley Public Policy Press, Berkeley, California, 2009.

[4] L. Godo, R. Lopez de Mantaras, C. Sierra, and A. Verdaguer, "MILORD: The Architecture and management of Linguistically expressed Uncertainty", International Journal of Intelligent Systems, 4 (1989) 471 - 501. 
[5] G. A. Miller, "The magical number seven plus or minus two: some limits on our capacity for processing information", Psychological Review, 63 (2009) $81-97$.

[6] P. M. Milner, Physiological psychology, Holt, NY, 1970.

[7] R. Trejo, V. Kreinovich, I. R. Goodman, J. Martinez, and R. Gonzalez, "A Realistic (Non-Associative) Logic And a Possible Explanations of $7 \pm 2$ Law", International Journal of Approximate Reasoning, 29 (2002) 235 266.

Received: September 29, 2013 